L'éducation relative à l'environnement auprès des adultes

\title{
Anishinaabeh pisiskatesi - L'adulte au cœur de ses pouvoirs
}

Dolorès Contré

\section{(2) OpenEdition \\ Journals}

Édition électronique

URL : https://journals.openedition.org/ere/7233

DOI : $10.4000 /$ ere. 7233

ISSN : 2561-2271

Éditeur

Centr'ERE

Référence électronique

Dolorès Contré, "Anishinaabeh pisiskatesi - L'adulte au cœur de ses pouvoirs », Éducation relative à

l'environnement [En ligne], Volume 16 - 1 | 2021, mis en ligne le 10 mars 2021, consulté le 28 mai 2021.

URL : http://journals.openedition.org/ere/7233; DOI : https://doi.org/10.4000/ere.7233 


\title{
Anishinaabeh pisiskatesi - L'adulte au cœur de ses pouvoirs
}

\author{
Dolorès Contré
}

1 Il m'apparait que le développement d'une identité écologique se déploie en l'adulte luimême. Je le perçois comme une personne active au sein de son milieu, qui agit de manière écoresponsable et écocitoyenne. Il est préoccupé par le bienêtre de sa famille et de sa communauté ainsi que des besoins de base pour la survivance de toutes et tous. Cette personne adulte possède en elle le pouvoir de modifier les structures et les cadres qui l'oppressent et de coopérer en réseau tout en réfléchissant sur des enjeux socioécologiques préoccupants afin de trouver des solutions créatives, puisées en partie dans ses expériences de vie. 


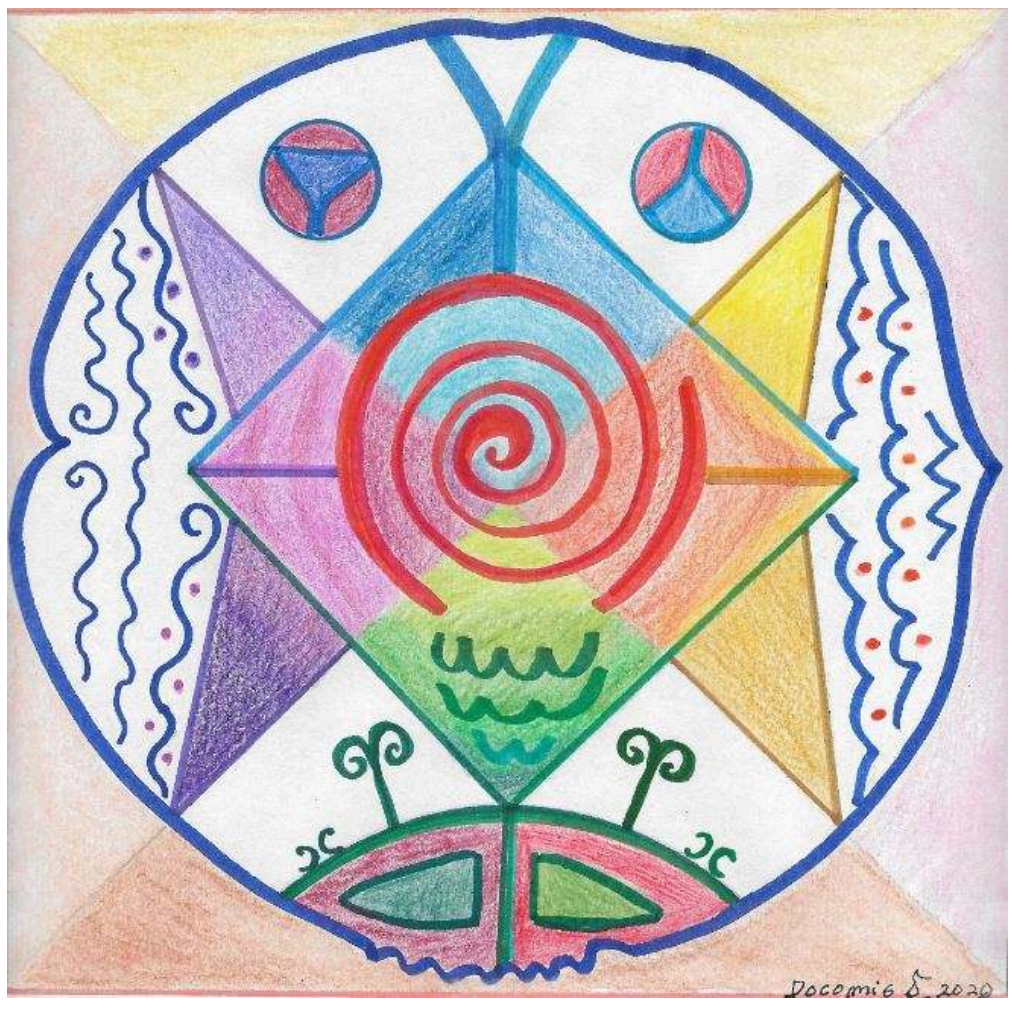

2 Au centre du dessin, la spirale illustre l'âme humaine en évolution, celle de la personne acteur-trice de changement. Ensuite, quatre pictogrammes intégrés les uns dans les autres forment un nouvel univers symbolique.

3 Le premier, symbole du féminin (en haut) et le second, symbole du masculin (en bas) forment un losange pour représenter l'égalité entre toutes les formes du vivant ainsi que la justice écosociale.

4 Le cercle est quant à lui une forme organique et naturelle, donnant à l'illustration une dimension concave et sombre par les couleurs de violet, mais aussi convexe et lumineuse par les couleurs jaune et orange, soit une sorte de dualité exprimée à travers les textes de ce numéro thématique, entre préoccupations et espoirs.

Ce cercle constitue un principe d'unité inclusif, le «Je/Nous »; il symbolise un espace commun où les efforts de l'humanité pour contrer la crise socioécologique sont représentés par le carré dont les extrémités font référence aux quatre points cardinaux. Les couleurs ont aussi été choisies pour identifier les quatre éléments, Air, Terre, Feu et Eau.

\section{BIBLIOGRAPHIE}

Contré Migwans, D. (2013). Une pédagogie de la spiritualité amérindienne : Naa-ka-nah-gay-win. Paris : Éditions L'Harmattan, collection « Écologie et formation » 


\section{AUTEUR}

\section{DOLORÈS CONTRÉ}

Dolorès Contré est une artiste interdisciplinaire et pédagogue franco-Anishinaabeh par ses grands- parents. Elle est chargée de cours sur les traditions spirituelles autochtones à l'Institut d'études religieuses de l'Université de Montréal. Son ouvrage Une pédagogie de la spiritualité amérindienne - Naa-ka-nah-gay-win (2013) porte sur un dialogue transdisciplinaire entre l'expression par les arts symboliques et l'écoformation. Dolorès Contré est également formatrice auprès des enseignant.e.s et de divers groupes sociaux. 